\title{
Acquiring Clitic Placement in Bilectal Settings: Interactions between Social Factors
}

OPEN ACCESS

Edited by:

Maria Garraffa,

Heriot-Watt University, UK

Reviewed by:

Alexandra Perovic,

University College London, UK

Ur Shlonsky,

Université de Genève,

Switzerland

*Correspondence:

Kleanthes K. Grohmann

kleanthi@ucy.ac.cy

Specialty section:

This article was submitted

to Language Sciences,

a section of the journal

Frontiers in Communication

Received: 16 December 2016

Accepted: 17 March 2017

Published: 12 April 2017

Citation:

Grohmann KK, Papadopoulou E and Themistocleous C (2017)

Acquiring Clitic Placement in

Bilectal Settings: Interactions

between Social Factors.

Front. Commun. 2:5.

doi: 10.3389/fcomm.2017.00005

\author{
Kleanthes K. Grohmann ${ }^{1,2 *}$, Elena Papadopoulou ${ }^{2,3}$ and Charalambos Themistocleous ${ }^{2,4}$ \\ ${ }^{1}$ University of Cyprus, Nicosia, Cyprus, ${ }^{2}$ Cyprus Acquisition Team, Nicosia, Cyprus, ${ }^{3}$ European University Cyprus, \\ Nicosia, Cyprus, ${ }^{4}$ University of Gothenburg, Gothenburg, Sweden
}

This article examines the development of object clitic placement by children acquiring Cypriot Greek. Greek-speaking Cyprus is sociolinguistically characterized by diglossia between two varieties of Greek, the local Cypriot Greek and the official Standard Modern Greek. Arguably as a result of this situation, clitics may be placed postverbally (enclisis) or preverbally (proclisis) in the same syntactic environment; while the former is a property of Cypriot Greek and the latter is typically considered an effect of the standard language. The following issues are investigated here: (a) how such bilectal speakers distinguish between the two Greek varieties with respect to clitic placement; (b) how the acquisition of clitics develops over time; (c) how, and which, sociolinguistic factors determine clitic placement; and (d) how schooling may affect clitic placement. To address (a)-(d), a sentence completion task was used to elicit clitic productions, administered to 431 children around Cyprus ranging from 2 years 8 months to 8 years 11 months. The C5.0 machine-learning algorithm was employed to model the interaction of (socio-)linguistic factors on the development of clitic placement. The model shows that speakers acquire the relevant features very early, yet compartmentalization of form and function according to style emerges only as they engage in the larger speech community. In addition, the effects of sociolinguistic factors on clitic placement appear gradually.

Keywords: acquisition of clitics, discrete bilectalism, sociolinguistic factors in language development, C5.0 algorithm, diglossia, socio-syntax of development hypothesis

\section{INTRODUCTION}

Language acquisition is assumed to proceed uniformly (Lenneberg, 1967). For example, across languages children between 6 and 8 months of age start to babble; at about 10-12 months, they produce and understand some words; and at around 2 years, they combine words. Even bilingual children follow the same path, though somewhat delayed [see, e.g., Tsimpli (2014) and responses]. This said, children acquiring language in bilingual settings have to tackle two major problems: (i) the extreme complexity imposed by the systemic and external variation in the input and (ii) the choice of the right code that suits the appropriate linguistic environment.

This study revisits the research presented in the study by Grohmann (2014a) on the acquisition of (preverbal vs. postverbal) object clitic placement in Cyprus, a sociolinguistically diverse environment, which is traditionally characterized by diglossia (Newton, 1972, in the sense of Ferguson, 1959), understood linguistically as "(discrete) bilectalism" (Rowe and Grohmann, 2013). In this environment, clitic placement displays features that are both Cypriot Greek (canonically enclisis) and Standard Modern Greek (proclisis by default). Unlike previous publications, this article embeds 
language variation and clitic acquisition more clearly within the Socio-Syntax of Development Hypothesis (Grohmann, 2011). The previously collected data are now completely reanalyzed. In particular, the statistical methods employed here offer a model of sociosyntactic variation and constitute a new proposal for analyzing language acquisition. In this sense, this study offers new insights in the acquisition of clitics: It includes the role of gender, age, and place of origin not as isolated properties but as factors that interact dynamically and influence the acquisition and subsequent development of object clitics in Greek Cypriot children. Only in this way we can understand the Socio-Syntax of Development Hypothesis as effects of multiple and dynamic social factors on linguistic variables: Each factor can have different significance with respect to the other factors.

This article is structured as follows. After a brief presentation of bilectalism, which characterizes the linguistic landscape in Cyprus, Section "Background" provides the background on basic properties of clitic placement in the two varieties of Greek and lays out the three experimental hypotheses pursued in this study. Section "The Present Study" introduces the study, including measurements and statistics employed, followed by a presentation of the main results in Section "Results." A thorough discussion follows in Section "Discussion," which also sketches a sociosyntactic model for the acquisition of clitic placement. Final remarks conclude the article.

\section{BACKGROUND}

\section{Discrete Bilectalism in Cyprus: Cypriot Greek (CG) and Standard Modern Greek (SMG)}

Cypriot Greek is the local variety of Greek spoken in Cyprus. It is often distinguished into "village CG" and "urban CG" (Newton, 1972). However, Hadjioannou et al. (2011) suggest that post-1974, regional varieties are in the process of being leveled out due to demographic and social changes, and a Pancyprian koiné variety is fast emerging [see also Tsiplakou (2014)]. They argue that urban CG-in their terminology, the Pancyprian koiné, perhaps what Arvaniti (2010) calls Cypriot Standard Greek (CSG) - stands in a diglossic relationship to $\mathrm{SMG}^{1}$ : CG is the sociolinguistic L(ow)variety, and SMG is the superimposed $\mathrm{H}$ (igh)-variety.

Hadjioannou et al. (2011) do not do full justice to local variability, though, that exists between village CG, namely the less prestigious varieties or basilects and the most prestigious urban CG (Newton, 1972; Goutsos and Karyolemou, 2004; Arvaniti, 2010). In addition, by assuming that SMG is the acrolectal form, they arguably presuppose that CG speakers should be perfect bilinguals, which

${ }^{1}$ Ferguson (1959, p. 336) defines diaglossia as "a relatively stable language situation in which, in addition to the primary dialects of the language (which may include a standard or regional standards), there is a very divergent, highly codified (often grammatically more complex) superposed variety, the vehicle of a large and respected body of written literature, either of an earlier period or in another speech community, which is learned largely by formal education and is used for most written and formal spoken purposes but is not used by any section of the community for ordinary conversation." is not the case (Arvaniti, 2010; Leivada et al., 2017, in press). Note that other than the many Greek citizens who live in Cyprus [29,321 as per the Statistical Service of Cyprus (CYSTAT) (2011) ${ }^{2}$, the Greek-speaking population of Cyprus employs the CG variety in one form or another on a regular basis, if not predominantly, in their day-to-day linguistic experiences.

Research initiated by Arvaniti (2010), including more recent work from our own research group (Grohmann and Leivada, 2012; Rowe and Grohmann, 2013, 2014; Leivada et al., 2017), provides a more refined account of the linguistic situation in Cyprus. Specifically, these studies consider as the H-variety "urban CG" or "CSG," which is more homogeneous and gains recognition as the more prestigious form of CG, compared to village CG, which is the true L-variety. This is not a new development; the distinction between unambiguous CG forms on the one hand and unambiguous SMG forms on the other hand were not always clear-cut. For example, when Newton described the sociolinguistic situation on the island during the 1960s, he suggested that the dialect features, alongside so-called SMG features, are often blurred: "[A]part from the quite considerable gap between village dialects and the strongly standardizing speech of urban Cypriots,/ xorkátika/[i.e., village CG-GPT] itself is often not heard in a pure form, but is interspersed with elements most conveniently regarded as belonging to standard Greek" (Newton, 1972, p. 108).

Furthermore, even in written language, which follows the conventions of SMG, CG speakers' output often displays features of the dialect (Arvaniti, 2010; Leivada et al., 2017, in press). In such a complex linguistic environment, the varieties do not have well-defined boundaries. Rowe and Grohmann (2013) suggest that because Greek Cypriots eventually tease apart the varieties and render complete compartmentalizations (able to distinguish between CSG and SMG), Cyprus is (still) diglossic. To capture the linguality of Greek Cypriots, Rowe and Grohmann (2013, 2014) propose the notion of "(discrete) bilectalism." To the extent that the term bilectalism is applied this way to the linguistic situation in Cyprus:

[I]t suggests dual competence of the varieties native to two polities (Greece and Cyprus) and their respective native varieties (SMG and CG). It also describes individual competencies in the two varieties [but nonrandomly, that is, crucially only-GPT] as a function of these individuals living and participating in this type of society.

$$
\text { (Grohmann, 2014a, p. 4) }
$$

CG and SMG differ most obviously in their phonetics, (morpho)phonology, and lexicon (e.g., Newton, 1972; Theodorou, 2007; Arvaniti, 2010). As for morphosyntax, there are also a large number of differences, but it is clitic placement that has arguably drawn the greatest attention (e.g., Agouraki, 1997, 2001; Terzi,

${ }^{2}$ Population census does not distinguish between CG and SMG; therefore, we employ citizenship as an indicative number of the population of SMG speakers In addition, the reported number increased with the economic crisis in Greece. 


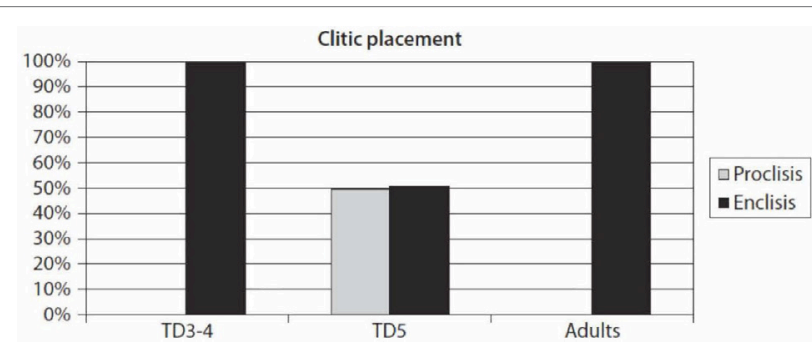

FIGURE 1 | Clitic placement in pilot study (Grohmann, 2011, p. 196).

TABLE 1 | Non-target placement across studies (Grohmann, 2014a, 25).

\begin{tabular}{llc}
\hline CAT study & $\begin{array}{c}\text { Mean age in } \\
\text { months (SD) }\end{array}$ & $\begin{array}{c}\text { Mean preverbal clitic } \\
\text { placement out of 12 (SD) }\end{array}$ \\
\hline Grohmann et al. (2012) & $60.83(13.56)$ & $3.28(4.08)$ \\
Agathocleous (2012) & $66.53(10.25)$ & $4.08(4.73)$ \\
Leivada et al. (2010) & $73.18(19.61)$ & $4.98(5.02)$ \\
Charalambous and & $79.29(10.95)$ & $6.00(5.08)$ \\
Agathocleous (2011, & & \\
Unpublished) & & $7.73(4.67)$ \\
Theodorou (2013) & $84.54(15.54)$ & $6.68(5.01)$ \\
Charalambous and & $86.76(9.00)$ & \\
Agathocleous (2012, & & \\
Unpublished) & & \\
\hline
\end{tabular}

${ }^{1}$ Charalambous, A. and M. Agathocleous (2011). The acquisition of clitics in Cypriot Greek children's language living in a rural setting. Unpublished ms., University of Cyprus, Nicosia.

${ }^{2}$ Charalambous, A. and M. Agathocleous (2012). The development and the role of the social environment in Cypriot Greek clitic placement: Factors and trends. Unpublished ms., University of Cyprus, Nicosia.

Apparent optionality in clitic placement in certain syntactic environments has also occasionally been noted for adult CG, culminating in separate (sociolinguistic) empirical investigations in which Pappas $(2012,2014)$ reports a certain level of variability. Yet, it would be misleading to characterize the two options of clitic placement as syntactic variants; after all, our research team's production tasks administered in CG almost invariably prompted enclisis, whereas the same task carried out in SMG led to proclisis (Leivada et al., 2010). This suggests that CG and SMG are discretely distinguished by speakers, each with its own grammatical rules. To the extent that there may be a blur between proclisis and enclisis in the speech of Greek Cypriots, we contend that this must be due to the still poorly understood exact acrolect or H-variety in the guise of CSG, SMG, or some mixed form(s). Future research across generations of speakers needs to clarify this issue employing insights from sociolinguistics and theoretical linguistics.

As Leivada and Grohmann (in press) note, there might be an obvious way to approach the situation in which both enclisis and proclisis are encountered in identical syntactic contexts by the same speakers: One might appeal to "competing grammars," a concept going back to Kroch (1994), who proposed competition of grammatical systems in diachronic change "between grammatically incompatible options which substitute for one another in usage" (p. 180); for specific accounts and extensions to language acquisition models, see Kroch and Taylor (2000),
Yang (2000), Legate and Yang (2007), among others. Note that Lightfoot (1999) characterized competing grammars to reflect "internalized diglossia"; hence, this might indeed be an appropriate approach to take up for CG. Competition of the CG and SMG grammatical systems has been explicitly suggested by Tsiplakou $(2009,2014)$. In our own work, we further enrich the model by integrating two related older notions, "competing motivations" (Du Bois, 1985) and "metalinguistic awareness" (Cazden, 1976).

Moreover, the competing grammars hypothesis would have children acquiring the native CG grammar (enclisis) face the emerging SMG grammar (proclisis). This just happens to grow stronger through increased input. Since formal schooling is carried out, by law, in the medium of SMG (but see Sophocleous, 2011), it is around the entrance into the school system that the SMG grammar becomes stronger, perhaps even dominant at times. We will turn to this next.

\section{Toward Capturing the Socio-Syntax of Development Hypothesis}

In an at first glance alternative approach, Grohmann (2011) proposed the Socio-Syntax of Development Hypothesis. According to subsequent refinements,

the [Socio-Syntax of Development Hypothesis] approaches the acquisition of syntactic variants that pertain to different varieties, in bi- $x$ environments, as proceeding through the existence of competing motivations that arise depending on the level of proximity (in the dialectal continuum) existing between the variety that the child is exposed to prior entering school and the one used in school-that is, even beyond the 'normal' period of native language acquisition.

(Grohmann and Leivada, 2012, p. 257)

In essence, the Socio-Syntax of Development Hypothesis holds that in the course of the language acquisition process, emergence of sociolinguistic and metalinguistic awareness as well as development of social identities account for children's sociolinguistic choices. Because both metalinguistic awareness and language acquisition develop over time, we expect this to be reflected in children's different linguistic choices. Moreover, we expect that, to a certain degree, social factors account for the particular choices (Nesdale and Rooney, 1996; Habib, 2016). An experiment has been designed to test these expectations. In the next section, we discuss the experimental hypotheses of this study.

Many sociolinguistic studies have investigated, among others, sex (male/female) or, as used here, gender differences between boys and girls in language development across heterogeneous populations. Earlier studies suggest that gender is a fundamental factor for variation (Maccoby and Jacklin, 1974; Fenson et al., 1994), whereas more recent ones claim the exact opposite (Hyde, 2005; Wallentin, 2009). In an attempt to resolve the debate, Barbu et al. (2015) investigated not only gender differences but also children's socioeconomic status (SES) who acquired a frequent phonological alternation in French between the ages of around 2.5 and 6.5 years. Gender differences were only found for children with low SES, whereas low-SES boys performed worse 
than low-SES girls. No such differences were observed in children with higher SES, suggesting the need for a better reorganization of conditions tested in language development.

Another factor commonly assumed to account for linguistic variation is the urban/rural dichotomy of children's habitation. A recent study by Habib (2016) showed the continuous use of urban Arabic features in rural children. In particular, girls predominantly used their mothers' urban feature, the glottal stop [?], in place of the rural voiceless uvular stop [q]. In contrast, boys reverted to the use of the rural variant. The distribution of these variants does not only depend on gender: The younger the children were, the more urban variants they produced, displaying a great decrease of urban variant production in the group of 12 to 14 year olds whose rural variant production was increased instead.

A further important aspect of sociolinguistic and educational linguistic research concerns the role of literacy in dialectal contexts. A pioneer in the area within the United States, Wolfram (1994) investigated the relationship between bidialectalism and literacy, mostly in pupil populations from African American Vernacular English-speaking background. Linguistic and cultural differences were found to be factors in poor reading abilities, but the work also offers perspectives on language variation for practitioners through noting grammatical differences in dialects or implications for instruction and assessment.

In Europe, too, the effect of monodialectal vs. bidialectal literacy is now being explored. To mention just one study, Vangsnes et al. (2017) deal with the two written standards of Norwegian, Bokmål (majority variety), and Nynorsk (minority variety). Children in Norway are schooled in one or the other variety, yet pupils schooled in Nynorsk acquire Bokmål simultaneously through extracurricular exposure, hence develop "bidialectal literacy." The authors correlate the results from standardized national tests in reading, arithmetic, and English for eighth graders, with information available on language of instruction and SES. The main finding is that Nynorsk pupils perform better than average, which the authors take to be an effect of the "bilingual advantage" in cognitive development-and, importantly with relevance for this study, that such an advantage may arise even in the case of two closely related varieties.

For further interesting research on the relation between executive control and language abilities in two closely related varieties, Sardinian and Italian, in the context of schooling, see the study by Garraffa et al. (2015). Although not directly linked to executive control abilities (i.e., the "bilingual advantage" in cognitive development), there is a growing body of work on literary development in Cyprus, too, which is sensitive to the native CG variety in the context of SMG-dominant reading and writing instruction in school (e.g., Tsiplakou, 2006; Hadjioannou et al., 2011). Current research from Greece for SMG connects performance on executive control tasks explicitly with literary skills for monolingual and bilingual children (Andreou, 2015; Andreou and Tsimpli, unpublished $^{3}$ ). Following up on a first study by Antoniou et al. (2016), this connection is also being investigated for bilectal,

${ }^{3}$ Andreou, M., and Tsimpli, I. M. (2015). Dominance, biliteracy and cognitive control: effects on bilingual children's narratives. Unpublished manuscript. bilingual, and monolingual children in several ongoing dissertations within the Cyprus Acquisition Team (CAT Lab).

In addition, the issue of schooling as a factor on language development does seem to get some recognition lately, even beyond the area of literacy and in more formal approaches to language acquisition. For example, Heycock et al. (2013) look at (new) language change on the Faroe islands, where Danish seems to influence the language of Faroese-speaking children with the onset of schooling - that is, as in Cyprus, clearly after the critical period of the first-language acquisition process. They tested 5- to 10-yearold Faroese children on grammaticality judg-ments and elicited productions of subordinate clauses, which seem to be undergoing a change from an Icelandic-like system to one like Danish, a change away from $V$ to $T$. The study shows that preschool children exhibit more of the Icelandic-like order than adults do, that is, the change takes place later [see also the study by Heycock and sorace (unpublished) ${ }^{4}$ on embedded V2 across the Scandinavian languages, where judgments tend to be gradient rather than variable].

The starting point of efforts exploring the "cognitive advantage" of bilectal children from Cyprus reported in the study by Antoniou et al. (2016) comes from the original findings on clitic placement by young school-age children (Grohmann, 2011), which has subsequently been researched with many more child populations and groups [summarized in the study by Grohmann (2014a)]. This article constitutes a comprehensive overview of the reported data with a novel statistical approach. Thus, it lays the foundations for the current research agenda of "comparative bilingualism" (Grohmann, 2014b) and the gradience of multilingualism across populations (Grohmann and Kambanaros, 2015), even if that is in and of itself not the focus of this contribution. As introduced above, the present focus is the acquisition and subsequent development of clitic production by children acquiring CG. Our aims are to first address the issue of how clitic placement interacts with factors such as gender, place of residence, and input factors, which govern language acquisition, and then to provide a model that predicts the development of clitic placement in CG.

\section{Experimental Hypotheses}

Before the age of 3 years, both CG- and SMG-acquiring children have mastered clitic production (Marinis, 2000; Petinou and Terzi, 2002; Leivada et al., 2010; Grohmann, 2011; Grohmann et al., 2012). Given the variation in a child's (socio)linguistic environment, a theory of language acquisition must thus provide an account of the cognitive processes, which take place when children employ alternative structures in their speech, and an account of the child's form-decision strategies in bilectal (bidialectal, bivariational, and possibly bilingual) settings that allow for alternative forms to coexist.

Our aim is twofold: to first address the puzzling issue of how clitic placement, a grammatical characteristic, interacts with factors such as gender, place of residence, and input factors that

\footnotetext{
${ }^{4}$ Heycock, C., and Sorace, A. (2007). Verb movement in Faroese: new perspectives on an old question. Unpublished manuscript. 
govern language acquisition and then to provide a model that predicts the development of clitic placement in CG. We will argue that the linguistic settings constitute competitive sociolinguistic environments in which linguistic codes and forms are in conflict and that these environments give rise to (sociolinguistic) decisions and learning solutions.

In line with these goals, the following three experimental hypotheses will be pursued to account for clitic placement in CG:

(H1) Hypothesis 1: Proclisis increases with chronological age. In fact, Grohmann et al. (2012) and Agathocleous et al. (2014) demonstrated that, as they grow up, children acquiring CG employ proclisis more often; this tendency culminates in teenagers who show $100 \%$ preference in enclisis. If this hypothesis is correct, chronological age is expected to determine clitic placement for two reasons: (i) because children master clitic placement as a part of their linguistic development and (ii) because, as they grow up, children acquire the sociolinguistic norms of their community. Therefore, linguistic properties that associate with the $\mathrm{H}$-variety, such as proclisis, will steadily increase in formal settings (including psycholinguistic experiments), whereas features that are associated with the L-variety, such as enclisis, will decrease.

(H2) Hypothesis 2: Proclisis increases with schooling level. This hypothesis is in line with the Socio-Syntax of Development Hypothesis (Grohmann, 2011). Because SMG (or CSG with SMG-like rules that differ from non-acrolectal CG in the relevant respect) is the standard variety and taught in schools, we expect that systematic teaching of SMG would effectuate the use of proclisis; otherwise proclisis will remain constant or will be used at a lesser degree than enclisis.

(H3) Hypothesis 3: The degree of proclisis and enclisis use depends on sociolinguistic factors. Accordingly, we expect the following:

(i) Because enclisis is a property of an L-variety, it is expected to index masculinity, whereas proclisis, associated with the $\mathrm{H}$-variety, is expected to index femininity. This claim is based on observations that women employ more standard variants than men (Trudgill, 1972; Labov, 2001), especially if the standard is also an innovative form for a given language community. Accordingly, we hypothesize that boys will employ enclisis as a male variant, whereas girls will employ proclisis as a female variant.

(ii) Speakers from rural areas will employ more enclisis to a greater degree than speakers who live in urban areas. This claim is in line with studies that suggest a distinction between village CG and urban CG (e.g., Newton, 1972; Hadjioannou et al., 2011); previous research on CG clitic acquisition suggests that urban vs. rural place of residence influences clitic placement (Agathocleous et al., 2014).

(iii) Gender and place of residence are not simplex phenomena but interact with each other (Eckert, 1999); hence, it is the interaction of these sociolinguistic factors that accounts for the acquisition of clitic placement.

\section{THE PRESENT STUDY}

\section{Participants}

In the testing period from 2008 to 2011 , a total of 431 children participated in the experiment; for a detailed description of all populations tested on this experiment and the CAT Clitics Corpus and references to published analyses, see the study by Grohmann (2014a). At the time of data collection, all participants were aged between 2 years and 8 months and 8 years and 11 months; they were all native acquirers of Cypriot Greek, had two Greek Cypriot parents, and were born and raised in CG-speaking Cyprus. The research was approved by the Cyprus Ministry of Education and Culture upon submission of the full description of the tool and protocol to the Pedagogical Institute. Parents and participating schools' headmasters and teachers involved provided their written consent after detailed letters of information concerning the research to be conducted; hence, additional ethics approval was deemed unnecessary at the time of data collection. Table 2 shows the distribution of speakers across different age groups, arranged here by chronological age in years.

To elicit responses from all CG varieties, data collection took place in both urban and rural areas across (the Greek-speaking part of) the island. Table 3 shows the number of speakers who participated in the study based on their place of residence (in alphabetical order).

\section{Methodology}

This study adapted the COST Action A33 Clitics-in-Islands testing tool (Varlokosta et al., 2016) so as to elicit the production of third person singular direct object clitics. ${ }^{5}$ The task comprises 19 items, 12 target structures preceded by two warm-ups and interspersed by 5 fillers. All target and warm-up structures were declarative sentences with a transitive verb, with one half in present tense and the other in past tense, as in (5) and its corresponding picture in Figure 2.

(5) I korua luni tin kamiloparðali tse i kamiloparðali engaӨari. Jati i kamilo parðali engaӨari? I kamiloparðali enga日ari jati i korua... [target response: plinisci tin or luni tin]

"The girl is washing the giraffe and the giraffe is clean. Why is the giraffe clean? The giraffe is clean because the girl..." [target response: washes it (= her-CL)]

The target clitic pronoun was produced inside a because-clause and invariably referred to a third person singular object mentioned in the experimenter's introduction.

\footnotetext{
${ }^{5}$ For the development of the tool within COST Action A33, with a clear crosslinguistic intention, the because-island was chosen to provide a context for obligatory clitic use (Varlokosta et al., 2016). The intention of setting up a syntactic island environment was to elicit clitics even in languages that frequently allow object drop, including the grammatical omission of clitics in European Portuguese, where it is supposed to be ungrammatical (Raposo, 1986). For discussion, see the study by Costa and Lobo (2014) who argue that comprehension tasks are better suited to detect the mastery of clitic production and placement, whether in regular object drop or in more complex island contexts.
} 
TABLE 2 | Participants.

\begin{tabular}{|c|c|c|c|c|c|}
\hline Participants & Number & Age range (mean) & Age range (SD) & Gender [female (F)/male (M)] & Urban/rural \\
\hline \multirow[t]{3}{*}{ 2-year olds } & 18 & 2 years 8 months to 2 years 11 months (38 months) & 3.5 months & $9 F$ & $7 \cup$ \\
\hline & & & & & $2 \mathrm{R}$ \\
\hline & & & & $9 \mathrm{M}$ & $8 U$ \\
\hline \multirow[t]{3}{*}{ 3-year olds } & 58 & 3 years to 3 years 11 months (51 months) & 3.1 months & $28 \mathrm{~F}$ & $14 U$ \\
\hline & & & & & $14 \mathrm{R}$ \\
\hline & & & & $30 \mathrm{M}$ & $17 \mathrm{U}$ \\
\hline & & & & & $31 \mathrm{R}$ \\
\hline & & & & $50 \mathrm{M}$ & $29 U$ \\
\hline & & & & & $21 R$ \\
\hline \multirow[t]{3}{*}{ 5-year olds } & 120 & 5 years to 5 years 11 months ( 73 months) & 3.8 months & $60 \mathrm{~F}$ & $44 U$ \\
\hline & & & & & $16 \mathrm{R}$ \\
\hline & & & & $60 \mathrm{M}$ & $40 U$ \\
\hline \multirow[t]{4}{*}{ 7-year olds } & 32 & 7 years to 7 years 11 months (96 months) & 3.9 months & $15 \mathrm{~F}$ & $10 U$ \\
\hline & & & & & $5 \mathrm{R}$ \\
\hline & & & & $17 \mathrm{M}$ & $14 U$ \\
\hline & & & & & $3 R$ \\
\hline \multirow[t]{4}{*}{ 8-year olds } & 10 & 8 years to 8 years 11 months (106 months) & 1.5 months & $7 \mathrm{~F}$ & $5 U$ \\
\hline & & & & & $2 \mathrm{R}$ \\
\hline & & & & $3 \mathrm{M}$ & $2 U$ \\
\hline & & & & & $1 \mathrm{R}$ \\
\hline \multirow[t]{2}{*}{ Total } & 431 & & & $227 \mathrm{~F}$ & $280 U$ \\
\hline & & & & $204 M$ & $151 R$ \\
\hline
\end{tabular}

TABLE 3 | Number of speakers by gender $\times$ place of residence.

\begin{tabular}{lcc}
\hline Place (population) & Female & Male \\
\hline Agia Fyla $(14,451)$ & 6 & 4 \\
Evrixu $(827)$ & 3 & 3 \\
Ipsonas $(11,117)$ & 2 & 2 \\
Kolossi $(5,651)$ & 9 & 9 \\
Larnaka $(51,468)$ & 37 & 40 \\
Limassol $(101,000)$ & 44 & 42 \\
Nicosia $(55,014)$ & 53 & 39 \\
Paphos $(32,892)$ & 33 & 22 \\
Paralimni $(14,963)$ & 29 & 30
\end{tabular}

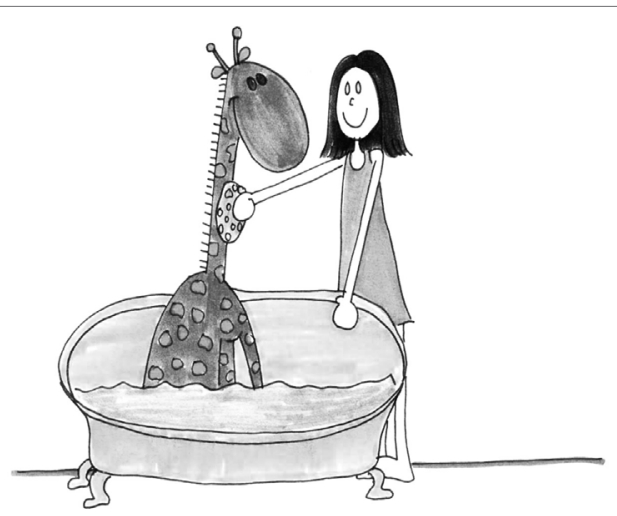

FIGURE 2 | Test picture used from COST A33 clitics-in-islands testing tool.
All tests were carried out by native speakers of CG. A total of five undergraduate and postgraduate students collected the data reported here. Testing lasted no longer than $5 \mathrm{~min}$ and was conducted in one session in a quiet room individually (child and researcher). Most children were tested at school, but a few younger ones were tested in their homes. To avoid a formal setting as much as possible and to obtain some kind of familiarity between experimenter and child, a brief conversation about a familiar topic, such as the child's favorite cartoons, took place before the testing.

The experimenter described each picture and then asked the participants to fill in the because-clause [see (5)]. The use of a clitic was expected; nevertheless, children also provided other responses: Some repeated jati "because" on their own, others filled in right after the experimenter's prompt of jati, and yet other children completed the sentence after the experimenter continued with the subject. In some instances, mainly after the third test item, children produced the clitic followed or preceded by the verb right after the question asked by the experimenter (Why is the giraffe clean?), that is, before the experimenter started uttering the because-clause. See also the study by Varlokosta et al. (2016) for more details.

No verbal reinforcement was provided during the test items other than encouragement with head nods and fillers. Participants received verbal feedback only during the two warm-ups at the beginning of the session. Self-correction was not registered; only the first response was recorded and used for data collection and analysis purposes. During the session, the researcher recorded the answers on a score sheet by hand; there was no audio or video recording. 


\section{Measurements}

The total number of participants amounts to 431 children; yet for the analysis, a number of productions were excluded based on the following criteria:

- The two warm-up items were removed from the data set, resulting in 12 test items.

- Productions that did not include a clitic were excluded from the data set.

- Productions with clitic placement restricted to a different environment were ignored (imperatives, subjunctives, and negation).

In total, 1,420 observations were excluded: 862 warm-up items, 429 productions that did not include a clitic, and 129 productions with clitic placement in a different environment. Thus, the final set comprises 5,580 observations. A database with the children's responses along with other sociolinguistic infor-mation was created. The database includes metadata such as the following:

A. Participants' response (12 levels/items); 12 target structures.

B. Date of testing; this provides the date of each testing session.

C. Researcher; to control for the effects of the researcher on clitic placements, code names for the five researchers who ran the experiment were encoded in the database.

In addition, the database contains the predictors and the response variables. The predictors were the following:

(6)

Speaker-Related Predictors
$\begin{array}{ll}\text { a. } & \text { Gender (two levels: Female/Male) } \\ \text { b. } & \text { Date of Birth and Age (in Months) } \\ \text { c. } & \text { Age Group (5-month groups) }\end{array}$

We employed a 5-month cut to facilitate more homogeneous grouping of children across age groups. This cut allowed for a more precise description of the groups and captured the gradual change in children's linguistic behavior, which is a result of the rapid linguistic development observed in children between 2 and 5 years of age.

(7) Demographic and geographical predictors

a. School Grade (6 levels: Nursery/Kindergarten/Pre-Primary/Grade 1) Grade 2/Grade 3). School grades associate with age. Observe that school grades presupposed different learning levels; therefore, children are expected to develop preverbal clitic placement as part of an SMG-learning process as they attend higher grades (see Grohmann, 2011). School would then boost the use of preverbal placement. In other words, we expect that school will embolden the learning of clitic placement in line with the Socio-Syntax of Development Hypothesis (Grohmann, 2011; Grohmann et al., 2012).

b. Residence (two levels: Town/Village). CG is often distinguished into rural/ village varieties and urban/town CG (Newton, 1972) or CSG (Arvaniti, 2010). The latter is the acrolectal form of the variety, whereas rural/village varieties are considered more basilectal. Speakers who live in rural areas are expected to employ enclisis more frequently than speakers who reside in urban centers (Agathocleous et al., 2014).

c. Area (2 levels: Rural/Urban). Because not all villages are considered rural areas, this factor aims to provide a better account for speakers' regional accents and registers.
The response variables are the following:

(8) a. Response (the actual response provided by children).

b. Clitic Production (3 levels: Production of clitic/No production of clitic/ Production of clitic in an obligatory context)

c. Clitic placement (2 levels: Preverbal placement/Postverbal placement)

\section{Statistics}

To estimate the contribution of the predictors such as School Grade, Gender, Residence, and Age Group on the classification of Clitic Placement, we employed the machine learning and classification algorithm C5.0, the output of which is a decision tree (Russell and Norvig, 2003, p. 653-677). For estimating the accuracy of the model, $90 \%$ of the data was run as a training test and the remaining $10 \%$ as a test set. To provide greater accuracy and better weighting, the model was enhanced using boosting with 100 trials, which results in more than one decision tree (Cohen, 1995). Note that C5.0 employs winnowing, which removes all those attributes that may be unhelpful. The final attributes employed in the model are thus those that contribute to the classification. The statistical analysis was implemented in R (R Core Team, 2012), with the $\mathrm{R}$ package $\mathrm{C} 50$ for the classification.

\section{RESULTS}

\section{Speaker-Related Predictors Age}

The findings from our earlier work (Grohmann, 2011) could be corroborated for the larger data set: Postverbal clitics clearly outnumber preverbal clitics in the responses of children aged between 30 and 40 months (Figure 3). Nevertheless, in the responses starting at 40 months, children's postverbal clitics steadily decrease, before becoming constant only between 45 and 50 months. Importantly, as the children grow up, the frequency of preverbal clitics increases in the responses, whereas postverbal clitics decrease.

Most importantly, Figure 3 shows a gradual decrease of postverbal alongside the corresponding rise of preverbal clitic placement. This transition takes place between 75 and 90 months of age. After 90 months (7 years 6 months), a dramatic decrease of postverbal placement takes place. After 100 months (8 years 6 months), postverbal placement increases again. We expect this rise to continue until $100 \%$ postverbal production achieved during puberty, as observed in the studies by Grohmann et al. (2012) and Agathocleous et al. (2014), who provide data, using the same testing tool, from adolescents who clearly settle for CG enclisis only.

\section{Gender}

The results concerning the effect of gender on clitic placement are reported in Table 4 . The percentage of postverbal clitic placement employed by male speakers (64\%) is greater than the percentage of postverbal clitic placement employed by female speakers (58\%). Most importantly, clitic placement differs significantly by gender, $\chi^{2}(1)=22.02, p<0.001$. 


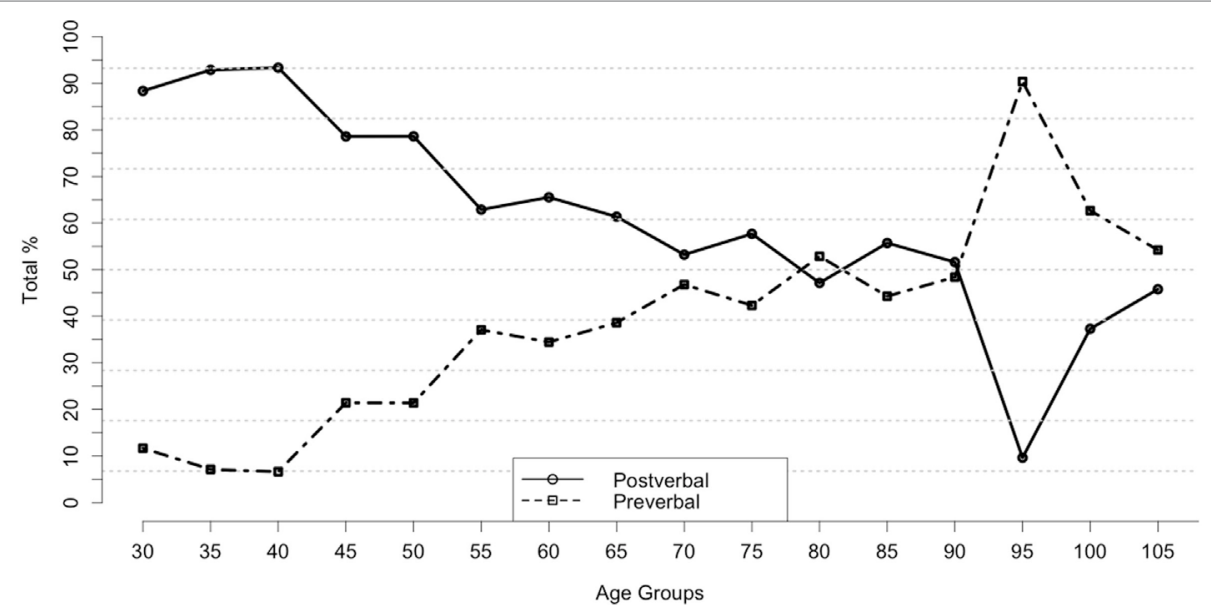

FIGURE 3 | Postverbal vs. preverbal clitic placement across 5-month age groups.

TABLE 4 | Clitic placement and gender.

\begin{tabular}{|c|c|c|c|c|c|}
\hline \multirow[t]{2}{*}{ Placement } & \multicolumn{2}{|c|}{ Female } & \multicolumn{2}{|c|}{ Male } & \multirow[t]{2}{*}{ Total } \\
\hline & $N$ & $\%$ & $N$ & $\%$ & \\
\hline Postverbal & 1,705 & 58 & 1,665 & 64 & 3,370 \\
\hline Preverbal & 1,260 & 42 & 950 & 36 & 2,210 \\
\hline
\end{tabular}

\section{Demographic and Geographical Predictors \\ Schooling}

Postverbal clitics outnumber preverbal clitics in the responses of children who attend nursery school (Figure 4). At kindergarten, caregivers rather than schools influence children's speech. Nevertheless, after kindergarten, preverbal clitics gradually appear more frequently in their speech, and by second grade, preverbal clitics are outnumbered by postverbal clitics (see also Grohmann et al., 2012; Agathocleous et al., 2014).

\section{Place of Residence}

Overall, speakers who live in towns employ fewer postverbal clitics (58.5\%) than speakers who live in villages (64\%). A Pearson chi-square test shows that the effect of place of residence on clitic placement is highly significant, $\chi^{2}(1)=14.69, p<0.001$.

Table 5 shows the effect of place of residence on clitic placement. This factor distinguishes speakers who reside in villages with rural accents from those who live in urban centers, and it better depicts regional sociolinguistic variation than the TownVillage dichotomy presented above. A Pearson chi-square test shows that the effect of place of residence on clitic placement is highly significant, $\chi^{2}(1)=13.85, p<0.001$.

\section{Decision Trees and Classification Structures}

The classification was performed with C5.0 (accuracy $=0.7,95 \%$ CI 0.6348-0.7537, kappa $=0.4$ ). The boosting for the classification was reduced to seven trials, as the other trials had no contribution. The attribute usage was the $100.00 \%$ for School Grade,
$100.00 \%$ for Chronological Age, $86.74 \%$ for Residence, and $85.49 \%$ for Gender.

In line with the preceding discussion, the decision tree shows that children younger than 50 months employ postverbal clitics, clearly conforming to CG (Figure 5).

Children of 50 months and older show greater variation in their choices. Specifically, the children who reside in villages and are younger than 90 months employ postverbal clitics, whereas children older than 90 months employ preverbal clitics. Gender becomes relevant for the selection of clitic placement in children who are born in towns. Boys attending first grade primarily employ postverbal clitics, whereas boys who attend nursery, kindergarten, pre-primary school, or primary school grades 1 and 2 primarily employ preverbal clitics. Girls younger than 60 months employ primarily postverbal clitics, whereas girls older than 65 months employ primarily preverbal clitics (i.e., possibly closer to SMG).

\section{DISCUSSION}

A theory of grammar should, on the one hand, explain children's ability to acquire their native language along with its core features and parametric intricacies and, on the other, account for their unique capacity to apply alternative forms in the appropriate contexts. This study shows that children learn the appropriate social settings very early in their lives and employ the suitable choices in the two alternative clitic placements. We suggest that the Socio-Syntax of Development Hypothesis achieves considerable explanatory success, corroborated by the findings of this study.

Returning to the issue of competing grammars, we suggest that the Socio-Syntax of Development Hypothesis constitutes an explicit "trigger" for the competition between two closely related grammars. In the present context, by identifying a schooling factor in the development of CG-speaking children's grammar, we can pinpoint the time frame in which the two systems (CG and SMG) compete and why so. Note that this grammatical development takes place past the critical period and arguably does so 


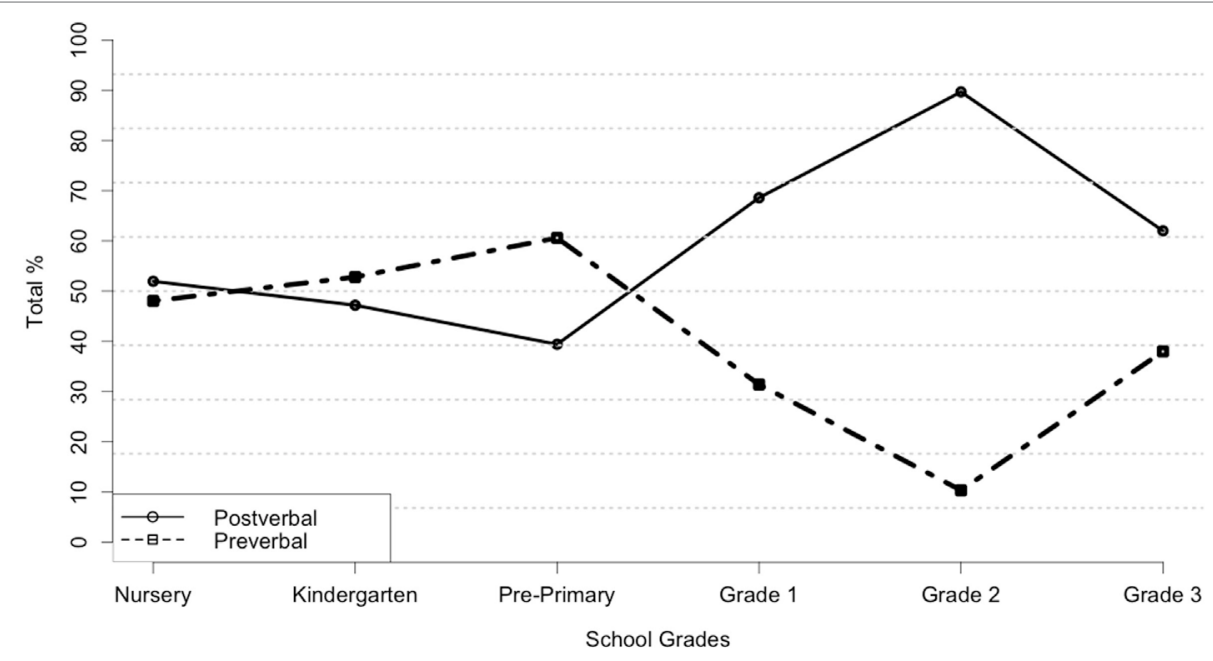

FIGURE 4 | Postverbal vs. preverbal clitic placement across school grades

TABLE 5 | Clitic placement and place of residence (town or village).

\begin{tabular}{lcccccc}
\hline Placement & \multicolumn{2}{c}{ Town } & & \multicolumn{2}{c}{ Village } & Total \\
\cline { 2 - 3 } \cline { 5 - 6 } & $\boldsymbol{N}$ & $\%$ & & $\mathbf{N}$ & $\%$ & \\
\hline Postverbal & 2,127 & 58.5 & & 1,243 & 64 & 3,370 \\
Preverbal & 1,509 & 41.5 & & 701 & 36 & 2,210 \\
Total & 3,636 & & & 1,944 & & 5,580
\end{tabular}

in conjunction with "competing motivations" (Grohmann and Leivada, 2012; Leivada and Grohmann, in press). These presumably stem from the (at least) two grammars in the bilectal child's linguistic development that compete with each other.

By showing that the linguistic choices of children depend on social factors, the tree-based model corroborates Grohmann's (Grohmann, 2011) and Grohmann and Leivada's (Grohmann and Leivada, 2012) formulations of the Socio-Syntax of Development Hypothesis by highlighting the interdependence between social factors and the acquisition of syntax. As such, it also demonstrates speakers' conditional adaptation to the microsociolinguistic environment. The microsociolinguistic environment depends on stable sociolinguistic environments that affect language learner linguistic habits during acquisition process. These environments include families, sociolinguistic communities, and periods of dramatic changes such as change to a new place (i.e., school), accompanied by a change in roles, sociolinguistic identities, power relationships, and so on, which call for adaptation in the child's sociolinguistic behavior. The conditional adaptation is what determines the choice of language form and triggers a dynamic break of a gradual process. To achieve this conditional adaptation, the speaker-hearer has to construct a representation of the environment and to employ this representation to assess the output productions. We suggest that this adaptation involves a learning procedure that accounts for parameter setting and also takes into account social variation to assess the use of the output forms. That is, we propose that the Socio-Syntax of Development Hypothesis accounts for the acquisition of linguistic phenomena that depend on which competing grammars will surface in a specific sociolinguistic context.

Next, we examine what the results of this study tell us about the experimental hypotheses put forth in Section "Experimental Hypotheses" above and the consequences of the model of these interactions. First, let us consider (H1). The results demonstrate that chronological age affects clitic placement acquisition, thus corroborating Hypothesis 1 (Grohmann et al., 2012; Agathocleous et al., 2014). Arguably, since clitic placement depends on the type of data (H-variety, L-variety, etc.), this effect is not simply quantitative but qualitative. Indeed, the results demonstrate that, as children grow up, proclisis associated with the H-variety (i.e., SMG or something close to it such as CSG) steadily increases in children's speech, whereas enclisis associated with the L-variety (i.e., CG) decreases. These observations suggest that children not only acquire the social norms of their communities along with their physiological, cognitive, and linguistic maturation but also observe these social norms in their speech.

What is more, the findings corroborate $(\mathrm{H} 2)$, namely that proclisis increases as children enter primary school (Grohmann et al., 2012; Agathocleous et al., 2014; Grohmann, 2014a). Children attending nursery school employ primarily postverbal patterns, which adhere to CG grammar, whereas preverbal placement appears to a lesser degree. After nursery school, as children attend higher grades, a gradual increase of proclisis and a gradual decrease of enclisis take place. At grade 1, children start to employ more preverbal than postverbal clitics in the present experimental context. This tendency continues in grades 2 and 3.

If we assume that proclisis is a property of SMG, its acquisition seems to depend on the role of formal education in the bilectal setting of Cyprus. Schools teach the standard language of the speech community, SMG (but see the study by Sophocleous (2011) and related studies). The role of formal education is considered an important contributing factor for L2 acquisition. Another issue that concerned especially studies on second dialect acquisition is whether the use of the native language or variety effectuates the acquisition of a second language or variety (Siegel, 2010). 


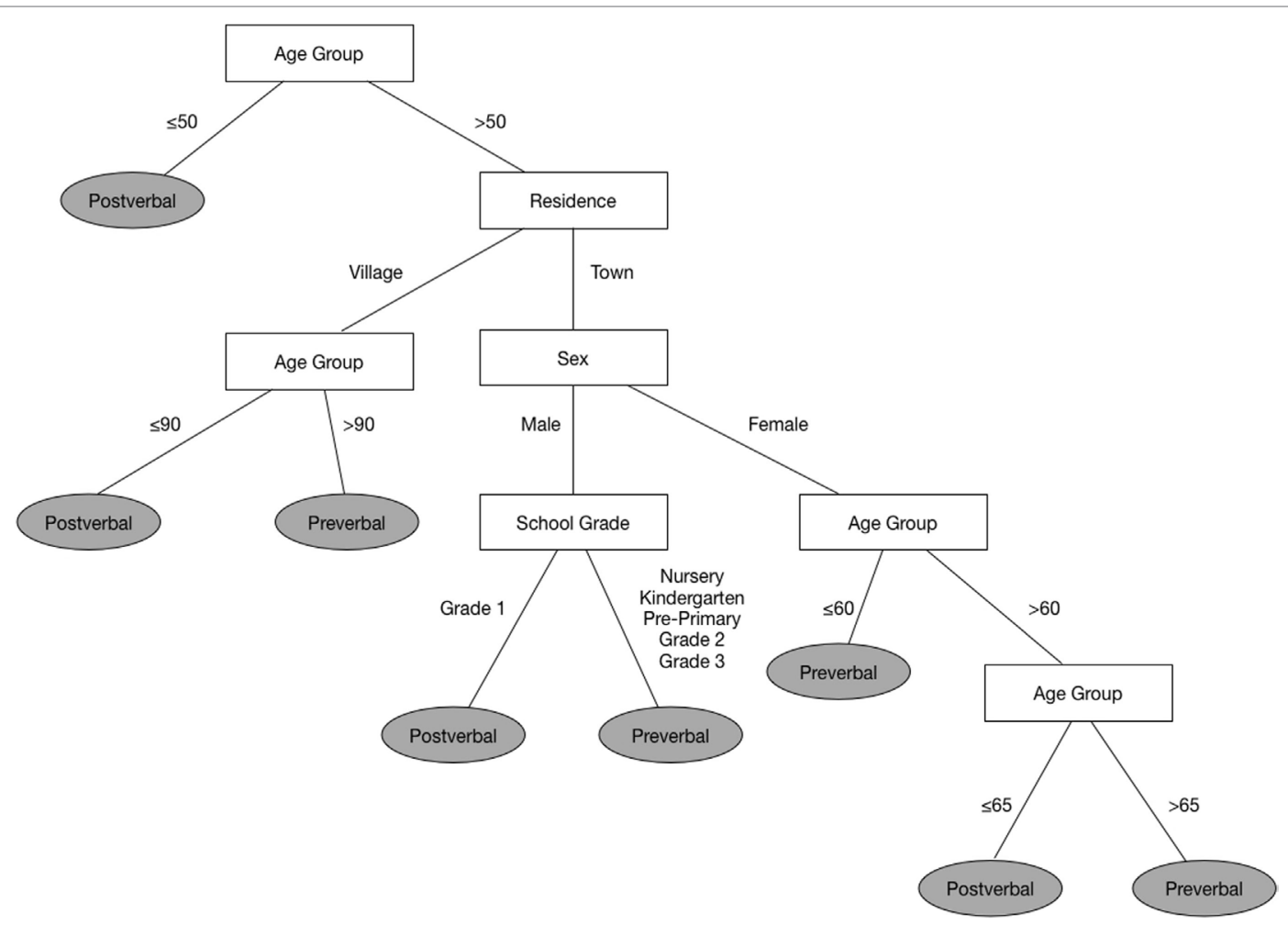

FIGURE 5 | C5.0 decision tree.

(H3) assumes an effect due to the interaction of social factors. It has become evident by now that social factors interact. But let us examine another case of this interaction. Strikingly, in 90- to 100 -month-old children (around 8 years), preverbal clitic placement increases dramatically, without obvious linguistic reason. Observe that the influence of sociolinguistic factors becomes more evident after 65 months, at around age 5 years 5 months. Boys employ enclisis to a greater degree than girls. Similarly, speakers who live in cities employ more standard and fewer marked forms than speakers who live in rural places. This finding suggests that girls adhere to standard forms from very early on, and they are more sensitive to norms and to prestigious and recognized forms [for further discussion, see, e.g., Trudgill (1972) or Labov (2001)].

Most importantly, at around 50 months, the place of residence plays a significant role (these effects are represented as a tree node for place of residence, which dominates gender). However, after 75 months of age, children begin to comprehend and appreciate gender roles, and to adhere to these; thus, they make language choices, which are represented as particular choices of clitic placement and acknowledge the social and linguistic environment. At around age of 8 years 4 months (100 months), children can discriminate standard from non-standard forms and appreciate the functions of these. In addition, they also have operational knowledge, namely to apply these distinctions in their everyday sociolinguistic practices and interactions [see also the studies by Reid (1978), Romaine (1978), or Payne (1980), among others, on early work regarding the effects of place of residence on children's linguistic choices].
When parallel structures exist in children's sociolinguistic environment (such as SMG, CSG, as well as basilectal and acrolectal varieties of CG), learning the target grammar involves a process of selection. Children develop language-specific practices as they grow up. At first, children follow the language of their caregivers, that is, the linguistic input found in children's immediate linguistic environment. But as they grow up and develop social skills, they become more communicative and (language-)competent members of society. In other words, they become more influenced by their immediate community: at first the wider family and, increasingly, friends from peer groups. This environment influences their linguistic behavior as they are reflected in the specific choices children make in clitic placement. Studies that include adolescents and preadolescents show a very similar pattern. Preadolescents tend to adopt more innovative variants, which peak in adolescence (Labov, 1994; Tagliamonte, 2012). This tendency affects most aspects of grammar, from phonology (Ash, 1982; Tagliamonte, 2012) to morphosyntax and discourse (Trudgill, 1974; Ash, 1982).

Overall, variation is inherent in monolingual and multilingual environments. Individual speakers acquire the characteristic frequency for particular variables from their caregivers. The behavior of speakers and that of the language community do not remain stable throughout speakers' lifetime (Tagliamonte, 2012, 49f). The frequency of different variables depends on the different stages of a speaker's life; it may increase in adolescence and even undergo reorganization (Labov, 1994). However, by late adolescence, a speaker's linguistic system stabilizes, and from that point onward, it is maintained for the rest of his or her life (Kirkham and 
Moore, 2013). Speakers between 30 and 55 years tend to employ more standard and fewer marked forms (Labov, 1994). In older age, non-prestigious forms may reappear as speakers relax and detach themselves from the need to confront to society's demands (Labov, 1994; Tagliamonte, 2012). Future research on bilectal linguistic behavior in Cyprus through the lifetime should address will undoubtedly shed further light on these issues.

\section{CONCLUSION}

The study examined the acquisition of clitic placement (preverbal vs. postverbal) in Cypriot Greek, which is characterized by diglossia/bilectalism. We raised the following questions: How does the acquisition of clitics develop over time? How do sociolinguistic factors such as gender (male/female) and habitation setting (urban vs. rural) determine clitic placement? How does schooling affect clitic placement? The results of the study presented social factors that interact during language acquisition, especially postcritical period when the two emerging grammars seem to compete.

By employing a learning and clustering approach, the analysis provides a perhaps better understanding of these interactions, captured by the Socio-Syntax of Development Hypothesis,

\section{REFERENCES}

Agathocleous, M. (2012). The role of the Social Environment in the Production of Clitics in Cypriot Greek within the COST Action A33 Testing Tool. MA thesis, University of Cyprus, Nicosia.

Agathocleous, M., Charalambous, A., Papadopoulou, E., and Grohmann, K. K. (2014). "The role of the social environment on linguistic development," in Developments in the Acquisition of Clitics, eds K. K. Grohmann and T. Neokleous (Newcastle upon Tyne: Cambridge Scholars Publishing), 41-86.

Agouraki, Y. (1997). “On the enclisis/proclisis alternation," in Proceedings of the 2nd International Conference on Greek Linguistics, eds G. Drachman, A. Malikouti Drachman, J. Fykias, and C. Klidi (Graz: W. Neugebauer Verlag), 393-404.

Agouraki, Y. (2001). "The position of clitics in Cypriot Greek," in Proceedings of the First International Conference of Modern Greek Dialects and Linguistic Theory (Patras, Greece, Oct. 12-14, 2000), eds A. Ralli, B. D. Joseph, and M. Janse (Patras: University of Patras), 1-17.

Andreou, M. (2015). The Effects of Bilingualism on Verbal and Non-Verbal Cognition: The Micro- and Macro-Structure of Narratives in the Weak and the Dominant Language of a Bilingual Child [Dissertation]. Thessaloniki: Aristotle University of Thessaloniki.

Antoniou, K., Grohmann, K. K., Kambanaros, M., and Katsos, N. (2016). The effect of childhood bilectalism and multilingualism on executive control. Cognition 149, 18-30. doi:10.1016/j.cognition.2015.12.002

Arvaniti, A. (2010). Linguistic practices in Cyprus and the emergence of Cypriot Standard Greek. Mediterr. Lang. Rev. 17, 15-45.

Ash, S. (1982). The Vocalization of/l/ in Philadelphia [Dissertation]. Philadelphia, PA: University of Pennsylvania.

Barbu, S., Nardy, A., Chevrot, J. P., Guellai, B., Glas, L., Juhel, J., et al. (2015). Sex differences in language across early childhood: family socioeconomic status does not impact boys and girls equally. Front. Psychol. 6:1874. doi:10.3389/ fpsyg.2015.01874

Cazden, C. B. (1976). "Play with language and metalinguistic awareness: One dimension of language experience," in Play: Its Role in Development and Evolution, eds J. S. Bruner, A. Jolly, and K. Sylva (New York: Basic Books), 603-608.

Chatzikyriakidis, S. (2010). Clitics in Four Dialects of Modern Greek: A Dynamic Account [Dissertation]. London: King's College.

Chatzikyriakidis, S. (2012). A dynamic account of clitic positioning in Cypriot Greek. Lingua. 122, 642-672. doi:10.1016/j.lingua.2012.01.008 which can be understood as the sociolinguistic trigger for the observed grammatical competition. Further research currently carried out under the first author's supervision investigates other aspects of bilectal grammar aiming to tie these to closer to both executive control abilities [cf. Antoniou et al. (2016), but also Garraffa et al. (2015)] and, more generally, a gradient scale of multilingualism (cf. Grohmann, 2014b; Grohmann and Kambanaros, 2015).

\section{ETHICS STATEMENT}

According to the local legislation in Cyprus, ethical approval was not required for this type of study. The study was, however, conducted in accordance with the declaration of Helsinki, and written informed consent was obtained from the parents of each participant.

\section{AUTHOR CONTRIBUTIONS}

KG envisioned the project, managed the research, and revised the paper. EP was responsible for data collection, compilation, and entry. CT ran the statistical analysis and wrote a first draft of the paper. Subsequently all authors worked on refining and revising the text. All authors approved the final version.

Cohen, W. W. (1995). "Fast effective rule induction," in Proceedings of the Twelfth International Conference on Machine Learning, eds A. Prieditis and S. J. Russell (San Francisco, CA: Kaufmann), 115-123.

Costa, J., and Lobo, M. (2014). "Crosslinguistic variation in the acquisition of null categories: Portuguese vs. Japanese," in Developments in the Acquisition of Clitics, eds K. K. Grohmann and T. Neokleous (Newcastle upon Tyne: Cambridge Scholars Publishing), 276-291.

Du Bois, J. A. (1985). “Competing motivations," in Iconicity in Syntax, ed. J. Haiman (Amsterdam: John Benjamins), 343-366.

Duarte, I., and Matos, G. (2000). "Romance clitics and the minimalist program," in Portuguese Syntax, ed. J. Costa (New York: Oxford University Press), 116-142. Eckert, P. (1999). Linguistic Variation as Social Practice. Oxford: Blackwell.

Fenson, L., Dale, P. S., Reznick, J. S., Bates, E., Thal, D. J., and Pethick, S. J. (1994). Variability in early communicative development. Soc. Res. Child Dev. 59, 1-173.

Ferguson, C. (1959). Diglossia. Word 15, 325-340. doi:10.1080/00437956.1959.1 1659702

Garraffa, M., Beveridge, M., and Sorace, M. (2015). Linguistic and cognitive skills in Sardinian-Italian bilingual children. Front. Psychol. 6:1898. doi:10.3389/ fpsyg.2015.01898

Goutsos, D., and Karyolemou, M. (2004). Introduction. Int. J. Soc. Lang. 168, 1-17. doi:10.1515/ijsl.2004.031

Grohmann, K. K. (2011). "Some directions for the systematic investigation of the acquisition of Cypriot Greek: A new perspective on production abilities from object clitic placement," in The Development of Grammar: Language Acquisition and Diachronic Change, eds E. Rinke and T. Kupisch (Amsterdam: John Benjamins), 179-203.

Grohmann, K. K. (2014a). "CAT research on object clitic placement: Where we are now?" in Developments in the Acquisition of Clitics, eds K. K. Grohmann and T. Neokleous (Newcastle upon Tyne: Cambridge Scholars Publishing), 1-40.

Grohmann, K. K. (2014b). Towards comparative bilingualism. Linguist. Approaches Biling. 4, 336-341. doi:10.1075/lab.4.3.06gro

Grohmann, K. K., and Kambanaros, M. (2015). The gradience of multilingualism in typical and impaired language development: positioning bilectalism within comparative bilingualism. Front. Psychol. 7:37. doi:10.3389/fpsyg. 2016.00037

Grohmann, K. K., and Leivada, E. (2012). "Interface ingredients of dialect design bi- $x$, socio-syntax of development, and the grammar of Cypriot Greek," in Towards a Biolinguistic Understanding of Grammar: Essays on Interfaces, ed. A. M. Di Sciullo (Amsterdam: John Benjamins), 239-262. 
Grohmann, K. K., Theodorou, E., Pavlou, N., Leivada, E., Papadopoulou, E., Martinez-Ferreiro, S., et al. (2012). "The development of clitic placement in Cypriot Greek and the romance connection," in Selected Proceedings of the Romance Turn IV Workshop on the Acquisition of Romance Languages, eds P. Prévost, L. Tuller, and R. Zebib (Newcastle upon Tyne: Cambridge Scholars Publishing), 128-152.

Habib, R. (2016). Bidirectional linguistic change in rural child and adolescent language in Syria. Dialectologia 16, 117-141.

Hadjioannou, X., Tsiplakou, S., and Kappler, M. (2011). Language policy and language planning in Cyprus. Curr. Issues Lang. Plan. 12, 503-569. doi:10.1080/ 14664208.2011.629113

Heycock, C., Sorace, A., Hansen, Z., and Wilson, F. D. (2013). Acquisition in variation (and vice versa): V-to-T in Faroese children. Lang. Acquis. 20, 5-22. doi:10.1080/10489223.2012.738741

Hyde, J. S. (2005). The gender similarities hypothesis. Am. Psychol. 60, 581-592. doi:10.1037/0003-066X.60.6.581

Kirkham, S., and Moore, E. (2013). "Adolescence," in The Handbook of Language Variation and Change, eds J. Chambers and N. Schilling (Oxford: WileyBlackwell), 277-296.

Kroch, A. (1994). "Morphosyntactic variation," in Papers from the 30th Regional Meeting of the Chicago Linguistics Society: Parasession on Variation and Linguistic Theory, eds K. Beals, J. Denton, R. Knippen, L. Melnar, H. Suzuki, and E. Zeinfeld (Chicago: Chicago Linguistics Society), 180-201.

Kroch, A., and Taylor, A. (2000). "Verb-object order in Middle English," in Diachronic Syntax: Models and Mechanisms, eds S. Pintzuk, G. Tsoulas, and A. Warner (Oxford: Oxford University Press), 132-163.

Labov, W. (1994). Principles of Linguistic Change, Vol. 1: Internal Factors. Oxford: Blackwell.

Labov, W. (2001). Principles of Linguistic Change, Vol. 2: Social Factors. Oxford: Blackwell.

Lascaratou, C. (1998). "Basic characteristics of Modern Greek word order," in Constituent Order in the Languages of Europe, ed. A. Siewierska (Berlin: Mouton de Gruyter), 151-171.

Legate, J., and Yang, C. (2007). Morphosyntactic learning and the development of tense. Lang. Acquis. 14, 315-344. doi:10.1080/10489220701471081

Leivada, E., and Grohmann, K. K. (in press). "Language acquisition in bilectal environments: competing motivations, metalinguistic awareness, and the socio-syntax of development hypothesis," in Variation in Language Acquisition, eds M. Katerbow and G. de Vogelaer (Amsterdam: John Benjamins).

Leivada, E., Kambanaros, M., Taxitari, L., and Grohmann, K. K. (in press). (Meta) linguistic abilities of bilectal educators: the case of Cyprus. Int. J. Biling. Educ. Biling.

Leivada, E., Mavroudi, P., and Epistithiou, A. (2010). "Metalanguage or bidialectism? Acquisition of clitic placement by Hellenic Greeks, Greek Cypriots and binationals in the diglossic context of Cyprus," in Proceedings of ISCA Tutorial and Research Workshop on Experimental Linguistics 2010, ed. A. Botinis (Athens: ISCA and the University of Athens), 97-100.

Leivada, E., Papadopoulou, E., Kambanaros, M., and Grohmann, K. K. (2017). The influence of bilectalism and non-standardization on the perception of native grammatical variants. Front. Psychol. 8:205. doi:10.3389/fpsyg.2017. 00205

Lenneberg, E. H. (1967). Biological Foundations of Language. New York: Wiley \& Sons.

Lightfoot, D. (1999). The Development of Language: Acquisition, Change, and Evolution. Oxford: Blackwell.

Lorenzo, G. (1994). Optionality in the placement of Asturian clitics. Catalan Work. Pap. Linguist. 4.1, 93-120.

Maccoby, E. E., and Jacklin, C. N. (1974). The Psychology of Sex Differences. Stanford, CA: Stanford University Press.

Marinis, T. (2000). The acquisition of clitic objects in Modern Greek: single clitics, double clitics, clitic left dislocation. ZAS Pap. Linguist. 15, 260-283.

Nesdale, D., and Rooney, R. (1996). Evaluations and stereotyping of accented speakers by pre-adolescent children. J. Lang. Soc. Psychol. 15, 133-154. doi:10.1177/0261927X960152002

Newton, B. E. (1972). Cypriot Greek: Its Phonology and Inflections. The Hague: Mouton.

Pappas, P. (2012). "An empirical perspective on Cypriot clitics," in Neoelliniki dialektologia [Modern Greek Dialectology], Vol. 6, eds C. Bezandakou and K. Minas (Athens: KSILK), 391-413.
Pappas, P. (2014). Exceptional clitic placement in Cypriot Greek: results from an MET study. J. Greek Linguist. 14, 190-211. doi:10.1163/15699846-01402002

Payne, A. C. (1980). "Factors controlling the acquisition of the Philadelphia dialect by out-of-state children," in Locating Language in Time and Space, ed. W. Labov (New York: Academic Press), 143-178.

Petinou, K., and Terzi, A. (2002). Clitic misplacement among normally developing and SLI children and the status of Infl heads. Lang. Acquis. 10, 1-28. doi:10.1207/S15327817LA1001_1

Philippaki-Warburton, I. (1985). Word order in Modern Greek. Trans. Phil. Soc. $83,113-143$

Raposo, E. (1986). "On the null object in European Portuguese," in Studies in Romance Linguistics, eds O. Jaeggli and C. Silva Corvalán (Dordrecht: Foris), 373-390.

R Core Team. (2012). R: A Language and Environment for Statistical Computing. Vienna: R Foundation for Statistical Computing. Available at: http:// www.R-project.org

Reid, E. (1978). "Social and stylistic variation in the speech of children: some evidence from Edinburgh," in Sociolinguistic Patterns in British English, ed. P. Trudgill (London: Arnold), 158-172.

Revithiadou, A. (2006). Prosodic filters on syntax: an interface account of second position clitics. Lingua. 116, 79-111. doi:10.1016/j.lingua.2004.08.017

Revithiadou, A., and Spyropoulos, V. (2008). Greek object clitic pronouns: a typological survey of their grammatical properties. STUF 61, 39-53.

Romaine, S. (1978). "Post-vocalic/r/ in Scottish English: sound change in progress," in Sociolinguistic Patterns in British English, ed. P. Trudgill (London: Arnold), $144-157$.

Roussou, A., and Tsimpli, I. M. (2006). On Greek VSO again. J. Linguist. 42, 317-354. doi:10.1017/S0022226706003914

Rowe, C., and Grohmann, K. K. (2013). Discrete bilectalism: towards co-overt prestige and diglossic shift in Cyprus. Int. J. Soc. Lang. 224, 119-142.

Rowe, C., and Grohmann, K. K. (2014). Canaries in a coal mine: native speakerhood and other factors as predictors of moribundity, death, and diglossic shift in Cypriot Greek. Mediterr. Lang. Rev. 21, 121-142.

Russell, S. J., and Norvig, P. (2003). Artificial Intelligence: A Modern Approach, 2nd Edn. Englewood Cliffs, NJ: Prentice Hall.

Siegel, J. (2010). Second Dialect Acquisition. Cambridge: Cambridge University Press.

Sophocleous, A. (2011). Two languages in the classroom: the inconsistency between national and local objectives in formal education in Cyprus. J. Lang. Identity Educ. 10, 266-281. doi:10.1080/15348458.2011.598129

Statistical Service of Cyprus (CYSTAT). (2011). Population Census. Population and Social Conditions. Nicosia. Available at: http://www.cystat.gov.cy/mof/ cystat/statistics.nsf/populationcondition_22main_en/populationcondition_ 22 main_en?OpenForm\&sub=2\&sel=2\#

Tagliamonte, S. (2012). Variationist Sociolinguistics: Change, Observation, Interpretation. Malden, MA: Wiley-Blackwell.

Terzi, A. (1999a). Clitic combinations, their hosts and their ordering. Nat. Lang. Linguist. Theory 17, 85-121. doi:10.1023/A:1006075626603

Terzi, A. (1999b). "Cypriot Greek clitics and their positioning restrictions," in Studies in Greek Syntax, eds A. Alexiadou, G. Horrocks, and M. Stavrou (Dordrecht: Kluwer), 227-240.

Theodorou, E. (2007). Phonetic Development of CG-Speaking Toddlers Ages 24 to 36 Months: A Longitudinal Study. M.Sc. thesis, University of Sheffield, Sheffield.

Theodorou, E. (2013). Specific Language Impairment in Cypriot Greek: Diagnostic and Experimental Investigations. $\mathrm{PhD}$ dissertation, University of Cyprus, Nicosia.

Theodorou, E., and Grohmann, K. K. (2015). Object clitics in Cypriot Greek children with SLI. Lingua. 161, 144-158. doi:10.1016/j.lingua.2014.11.011

Trudgill, P. (1972). Sex, covert prestige and linguistic change in the urban British English of Norwich. Lang. Soc. 1, 179-195. doi:10.1017/S0047404500000488

Trudgill, P. (1974). The Social Differentiation of English in Norwich. Cambridge: Cambridge University Press.

Tsimpli, I. M. (2014). Early, late or very late: timing acquisition and bilingualism. Linguist. Approaches Biling. 4, 393-402. doi:10.1075/lab.4.3.01tsi

Tsiplakou, S. (2006). The emperor's old clothes: linguistic diversity and the redefinition of literacy. Int. J. Humanit. 2, 2345-2352.

Tsiplakou, S. (2009). "Language alternation, competing grammars and interlanguage: another facet of the Cyprus problem," in Proceedings of the 8th 
International Conference on Greek Linguistics, eds G. Giannakis, M. Baltazani, G. Xydopoulos, and T. Tsangalidis (Ioannina: University of Ioannina), 1195-1209. Tsiplakou, S. (2014). How mixed is a 'mixed' system? The case of the Cypriot Greek koiné. Linguist. Var. 14, 161-178. doi:10.1075/lv.14.1.07tsi

Vangsnes, ØA., Söderlund, G. B. W., and Blekesaune, M. (2017). The effect of bidialectal literacy on school achievement. Int. J. Biling. Educ. Biling. doi:10.1080/ 13670050.2015.1051507

Varlokosta, S., Belletti, A., Costa, J., Friedmann, N., Gavarró, A., Grohmann, K. K., et al. (2016). A cross-linguistic study of the acquisition of clitic and pronoun production. Lang. Acquis. 23, 1-26. doi:10.1080/10489223.2015.1028628

Wallentin, M. (2009). Putative sex differences in verbal abilities and language cortex: a critical review. Brain Lang. 108, 175-183. doi:10.1016/j.bandl.2008.07.001

Wolfram, W. (1994). "Bidialectal literacy in the United States," in Adult Biliteracy in the United States, ed. D. Spener (Washington, DC; McHenry, IL: Center for Applied Linguistics and Delta Systems), 71-88.
Yang, C. (2000). Internal and external forces in language change. Lang. Var. Change 12, 231-250. doi:10.1017/S0954394500123014

Conflict of Interest Statement: The authors declare that the research was conducted in the absence of any commercial or financial relationships that could be construed as a potential conflict of interest.

Copyright (c) 2017 Grohmann, Papadopoulou and Themistocleous. This is an open-access article distributed under the terms of the Creative Commons Attribution License (CC BY). The use, distribution or reproduction in other forums is permitted, provided the original author(s) or licensor are credited and that the original publication in this journal is cited, in accordance with accepted academic practice. No use, distribution or reproduction is permitted which does not comply with these terms. 